\title{
SLC11A1 : Gene Polymorphism and Progression of Fibrosis in Hepatitis C
}

\author{
Sahar A El-Nemr ${ }^{1}$, Sherief M Galal ${ }^{1}$, Hesham Atia ${ }^{2}$, \\ Yousry Abo-Elmagd \\ ${ }^{I}$ Tropical Medicine Department, Faculty of Medicine, Zagazig University,Egypt \\ ${ }^{2}$ Internal Medicine Department, Faculty of Medicine, Zagazig University, Egypt. \\ ${ }^{3}$ Medical Biochemistry Department, Faculty of Medicine, Zagazig University, Egypt.
}

Corresponding Author Sahar A El-Nemr

Mobile:+2007246450

\section{E mail:}

sahar.alnimr@yahoo.c om

Key words: Chronic Hepatitis C virus, Solute carrier 11a1 (SLC11A1), gene polymorphism
Background and study aim : Chronic Hepatitis $\mathrm{C}$ virus (HCV) infection is typically characterized by slowly progressive hepatic fibrosis. However, it is recognized that some patients do not progress while others rapidly develop significant fibrosis. Immune response mechanism in the control of viral replication and persistence in $\mathrm{HCV}$ induced liver disease has been well documented. Solute carrier 11a1 (SLC11A1) plays an immunomodulatory role in influencing macrophage activation status and the $\mathrm{T}$ helper $1 / \mathrm{T}$ helper 2 biases. It modulates the susceptibility to infectious/autoimmune diseases. The study aimed to: Analyze the possible involvement of polymorphism in the promoter regions of the SLC11A1 gene in the susceptibility for chronic hepatitis $\mathrm{C}$ infection and the progression of fibrosis in these patients.

Patients and methods: This study included 138 subjects. They were classified into 2 groups: Group I that included 69 matched apparently healthy persons and Group II that included 69 chronic hepatitis $\mathrm{C}$ patients (Child A) and was divided into 2 subgroups: Group (IIA): It included 35 chronic hepatitis $\mathrm{C}$ patients without fibrosis and Group (IIB): It included 34 chronic hepatitis $\mathrm{C}$ patients with fibrosis. All individuals were subjected to: Full

\section{INTRODUCTION}

Hepatitis $\mathrm{C}$ virus (HCV) is recognized as a major cause of chronic liver disease [1]. Patients with hepatitis $\mathrm{C}$ may have chronic hepatitis for as long as 40 years before progressing to cirrhosis [2].

Once cirrhosis occurs, hepatocellular carcinoma (HCC) develops in 1-4\% of these patients per year. It was estimated that HCV was attributable to one thirds of HCC cases [1]. history taking, complete physical and clinical examination, abdominal ultrasound, fibroscan, routine laboratory investigations, viral markers and determination of SLC11A1 promoter gene polymorphism.

Results: The present study demonstrated that no statistically significant difference was observed in the distribution of SLC11A1 genotype frequencies among patient and control groups, suggested absence of association between the presence of the polymorphism and the prevalence of disease. Moreover, chronic hepatitis C patients who had SLC11A1 2/2 genotype were significantly at decreased risk to develop fibrosis 0.2 times than those who had 3/3 genotype [OR:0.2, CI:(0.52-0.79)] suggesting that the $2 / 2$ genotype is associated with an decreased susceptibility to develop fibrosis.

Conclusion and recommendations: SLC11A1 gene promoter polymorphism could influence fibrosis progression in chronic hepatitis $\mathrm{C}$ in that the homozygous genotype $2 / 2$ exerts a protective effect against cirrhosis development. Gene therapy may have an important role in the treatment and prognosis of $\mathrm{HCV}$ infection which need further studies.

Egypt has a very high prevalence of HCV and a high morbidity and mortality from chronic liver disease, cirrhosis, and HCC [3]. Increasing the treatment capacity would further reduce the burden of $\mathrm{HCV}$ disease [4].

Chronic hepatitis $\mathrm{C}$ virus infection is typically characterized by slowly progressive hepatic fibrosis. However, it is recognized that some patients do not progress while others rapidly develop significant fibrosis. The major morbidity and mortality of persistent 
HCV infection occurs after the establishment of hepatic fibrosis and the subsequent occurrence of cirrhosis and HCC [5]. So, assessment of factors that could influence the rate of fibrotic progression is necessary.

The pathogenesis of HCV induced hepatic injury remains unclear but the major role played by the immune response mechanism in the control of viral replication and persistence in $\mathrm{HCV}$ induced liver disease has been well documented [6].

Natural resistance-associated macrophage protein 1(NRAMP1), now strictly referred to as SLC11A1 (Solute carrier 11a1) and the gene which encodes for it is recognized as having a role in the susceptibility of human and animals to a number of infections [7].

The Slc11a1 gene product seems to have a direct antimicrobial effect, but it also has pleiotropic effects that include macrophage activation and regulation of the Th1:Th2 balance of the adaptive immune response to intracellular pathogens [8]. SIC11A1 appears to influence major histocompatibility complex (MHC) class II molecules and cytokines such as tumor necrosis factor (TNF $\alpha$ ), interleukin (IL-1b) which regulate antigen presentation [8].

So we aimed to analyze the possible involvement of polymorphism in the promoter regions of the SLC11A1 gene in the susceptibility for chronic hepatitis $\mathrm{C}$ infection and the progression of fibrosis in these patients.

\section{PATIENTS AND METHODS}

This study was carried out in Tropical, Internal Medicine and Medical Biochemistry Departments, Faculty of Medicine, Zagazig University during the period from January 2014 to February 2015.

\section{Subjects :}

- It is a cross sectional comparative study that included 138 subjects.

- An informed consent was obtained from all individuals who shared in this study.

- Subjects were classified into 2 groups:

- Group I: Non hepatic group that included 69 matched apparently healthy persons as a control group.

- Group II: This group included 69 chronic hepatitis $\mathrm{C}$ patients (Child A according to Child Pugh -Turcotte classification) and was divided into 2 subgroups:

- Group (IIA): It included 35 chronic hepatitis $\mathrm{C}$ patients without fibrosis.

- Group (IIB): It included 34 chronic hepatitis $\mathrm{C}$ patients with fibrosis.

Child-Pugh-Turcotte classification: By using parameter of serum bilirubin, serum albumin, prothormbin time (PT)/International Normalizing Ratio (INR), hepatic encephalopathy and ascites [9] (Table 1).

Table (I): Child-Pugh-Turcotte criteria

\begin{tabular}{|l|c|c|c|}
\hline & 1 Point & 2 Points & 3 Points \\
\hline Albumin (g/dl) & $>3.5$ & $2.8-3.5$ & $<2.8$ \\
\hline Bilirubin (mg/dL) & $<2$ & $2-3$ & $>3$ \\
\hline Ascites & None & Minimal & Moderate \\
\hline Encephalopathy & None & Grade 1-2 & Grade 3-4 \\
\hline PT (second prolonged) & $<4$ & $4-6$ & $>6$ \\
INR & $<1.7$ & $<1.7-2.3$ & $>2.3$ \\
\hline
\end{tabular}

PT: Prothrombin time

INR: International Normalizing Ratio

Class A: 5-6 points; class B: 7-9 points; class C: 10-15 points

\section{Inclusion criteria:}

Patients with proven chronic hepatitis $\mathrm{C}$ infection were diagnosed on the basis of laboratory investigation. Fibrosis was diagnosed by liver biopsy that already present with the patients, abdominal ultrasound and fibroscan.
Exclusion criteria:

- Patients with alcohol consumption.

- Patient treated with interferon or with other antiviral drugs.

- Patients with hepatitis B coinfection.

- Patients who refuse to sign the informed written consent. 


\section{Methods}

All individuals were subjected to the following :

1- Full history.

2- Complete physical and clinical examination.

3- Abdominal ultrasound: using Aloka SSD-200 (a $3.5 \mathrm{MHz}$ transducer).

4- FibroScan 502 (E100M017.2-Version 2, software Version A 2.0): It is a non invasive, rapid painless method allowing evaluation of liver fibrosis by measurement of liver stiffness. Stiffness is expressed in kiopascals (kPs). Metavir histological index of grading fibrosis classifies fibrosis on a scale of F0 to F4 where F0 is normal liver without fibrosis and F4 represent liver cirrhosis.

5- Laboratory investigations including:

- Complete blood count (CBC) by cell counters Sysmex 21.

- Complete liver and kidney function tests by automated analyzer Advia 120 Semens and prothrombin time by automated coagulometer CA-1500.

- Viral markers.

6- Special investigations:

- Determination of SLC11A1 promoter Gene Polymorphism by PCR amplification according to (Kazunobu et al., 2003), followed by gel electrophoresis using Submarine Gel Electrophoresis System (Pharmacia Biotech by SEMKO AB, Sweden) and submarine chamber (Maxicell, EC360, M-E-C apparatus Co. St Petersburg, Florida, USA), Photographed under ultraviolet transillumination (Heralab $\mathrm{GmbH}$ laborgeratetransilluminator, Germany).

- Three alleles 162 bp (allele 1), 152bp (allele2) and $130 \mathrm{bp}$ (allele3) were identified in Egyptian population.

\section{Statistical Analysis}

All data were analyzed using SPSS 15.0 for windows (SPSS Inc., Chicago, IL, USA). Quantitative data were expressed as the mean \pm SD \& median (range), and the categorical data were expressed as a number (percentage). Chisquare $\left(\chi^{2}\right)$ test was used for comparison between groups (qualitative variable). A $\mathrm{P}$ value $<0.05$ was considered statistically significant, $\mathrm{P}<0.005$ was considered highly statistically significant, and $\mathrm{P}>0.05$ was considered non statistically significant. Odd ratio (OR) was used to estimate risk in univariate model with $95 \%$ confidence interval. If interval contain 1 , the $\mathrm{p}$ value of test statistics will be non-significant.

\section{RESULTS}

Table (2): Demographic characteristics of the studied groups

\begin{tabular}{|c|c|c|c|c|c|c|}
\hline \multirow{2}{*}{$\begin{array}{c}\text { Demographic } \\
\text { Data }\end{array}$} & \multicolumn{2}{|c|}{$\begin{array}{l}\text { Control } \\
\text { (group I) }\end{array}$} & \multicolumn{2}{|c|}{$\begin{array}{c}\text { Chronic hepatitis C } \\
\text { without fibrosis (group IIa) }\end{array}$} & \multicolumn{2}{|c|}{$\begin{array}{l}\text { Chronic hepatitis C with } \\
\text { fibrosis (group IIb) }\end{array}$} \\
\hline & \multicolumn{2}{|c|}{$N=69$} & \multicolumn{2}{|c|}{$\mathrm{N}=35$} & \multicolumn{2}{|c|}{$\mathrm{N}=34$} \\
\hline $\begin{array}{l}\text { Age (years) } \\
\text { Mean } \pm \text { SD } \\
\text { Range }\end{array}$ & \multicolumn{2}{|c|}{$\begin{array}{c}49.6 \pm 5.97 \\
(40-58)\end{array}$} & \multicolumn{2}{|c|}{$\begin{array}{l}50.57 \pm 5.12 \\
\quad(43-61)\end{array}$} & \multicolumn{2}{|c|}{$\begin{array}{c}51.29 \pm 4.96 \\
(45-60)\end{array}$} \\
\hline Sex & No & $\%$ & No & $\%$ & No & $\%$ \\
\hline $\begin{array}{l}\text { Male } \\
\text { Female }\end{array}$ & $\begin{array}{l}45 \\
24\end{array}$ & $\begin{array}{l}65.2 \\
34.8\end{array}$ & $\begin{array}{l}21 \\
14\end{array}$ & $\begin{array}{l}60 \\
40\end{array}$ & $\begin{array}{l}19 \\
15\end{array}$ & $\begin{array}{l}55.8 \\
44.2\end{array}$ \\
\hline
\end{tabular}

Regarding Genotypes of SLC11A1 promoter gene polymorphism in chronic hepatitis C and control groups:

SLC11A1 promoter genotypes $(3 / 3,2 / 3,2 / 2)$ represent $>97 \%$ of all detected genotypes in all studied groups. 
Table (3): Distribution of SLC11A1 promoter genotypes among chronic hepatitis C and control groups

\begin{tabular}{|l|c|c|c|c|c|c|}
\hline \multirow{2}{*}{$\begin{array}{c}\text { SLC 11A1 promoter } \\
\text { Genotypes }\end{array}$} & \multicolumn{2}{c|}{$\begin{array}{c}\text { Control } \\
\text { (group I) No=69 }\end{array}$} & \multicolumn{2}{c|}{$\begin{array}{c}\text { Chronic hepatitis C } \\
\text { (group II) } \\
\text { No=69 }\end{array}$} & \multirow{2}{*}{$\mathbf{X}^{\mathbf{2}}$} & \multirow{2}{*}{$\mathbf{P}$} \\
\cline { 2 - 6 } & $\mathbf{N o}$ & $\mathbf{\%}$ & No & $\mathbf{\%}$ & & \\
\hline Homozygous 3/3 & 29 & 42 & 32 & 46.4 & & \multirow{2}{*}{0.24} \\
\hline Heterozygous 2/3 & 24 & 34.8 & 28 & 40.6 & 2.7 & \\
\hline Homozygous 2/2 & 14 & 20.3 & 8 & 11.6 & & \\
\hline
\end{tabular}

No statistically significant difference was observed in the distribution of SLC11A1 genotype

frequencies among patient and control groups Chi square (X2) was 2.7 and P value was (0.24).

Table (4): Odds ratio (95\% CI) of SLC11A1 promoter genotypes between control group and chronic hepatitis $\mathrm{C}$ group

\begin{tabular}{|c|c|c|c|c|}
\hline $\begin{array}{c}\text { SLC11A1 promoter } \\
\text { genotypes }\end{array}$ & $\begin{array}{c}\text { Control } \\
\text { (group I) } \\
\text { No=69 }\end{array}$ & $\begin{array}{c}\text { Chronic hepatitis C } \\
\text { (group II) } \\
\text { No=69 }\end{array}$ & OR (95\% CI) & P \\
\hline $3 / 3$ & 29 & 32 & $1.07(0.57-1.97)$ & 0.477 \\
\hline $2 / 3$ & 24 & 28 & $0.54(0.23-1.25)$ & 0.11 \\
\hline $2 / 2$ & 14 & 8 & $0.51(0.22-1.19)$ & 0.088 \\
\hline
\end{tabular}

Table (5): Distribution of SLC11A1 promoter genotypes among chronic hepatitis C group without fibrosis and chronic hepatitis $\mathrm{C}$ group with fibrosis

\begin{tabular}{|c|c|c|c|c|c|c|}
\hline \multirow[t]{2}{*}{$\begin{array}{l}\text { SLC11A1 promoter } \\
\text { genotypes }\end{array}$} & \multicolumn{2}{|c|}{$\begin{array}{c}\text { Chronic hepatitis C } \\
\text { without fibrosis } \\
\text { (group II a) } \\
\text { No=35 }\end{array}$} & \multicolumn{2}{|c|}{$\begin{array}{c}\text { Chronic hepatitis C } \\
\text { group with fibrosis } \\
\text { ( group II b) } \\
\text { No=34 }\end{array}$} & \multirow[t]{2}{*}{$\mathbf{X}^{2}$} & \multirow[t]{2}{*}{$\mathbf{P}$} \\
\hline & No & $(\%)$ & No & $(\%)$ & & \\
\hline $3 / 3$ & 13 & 37.1 & 19 & 55.9 & \multirow{3}{*}{7.6} & \multirow{3}{*}{$0.022^{*}$} \\
\hline $2 / 3$ & 15 & 42.9 & 13 & 38.2 & & \\
\hline $2 / 2$ & 7 & 20 & 1 & 2.9 & & \\
\hline
\end{tabular}

The frequency of SLC11A1 2/2 genotype was significantly decreased in chronic hepatitis C group with fibrosis as compared to chronic hepatitis $\mathrm{C}$ group without fibrosis (Chi square (X2) was 7.6 and $\mathrm{P}$ value $<0.05)$.

Table (6): Odds ratio (95\% CI) of SLC11A1 promoter genotypes between chronic hepatitis C group without fibrosis and chronic hepatitis $\mathrm{C}$ group with fibrosis

\begin{tabular}{|l|c|c|c|c|}
\hline $\begin{array}{c}\text { SLC11A1 promoter } \\
\text { genotype }\end{array}$ & $\begin{array}{c}\text { (Group IIa) } \\
\text { No=35 }\end{array}$ & $\begin{array}{c}\text { (Group IIb) } \\
\text { No=34 }\end{array}$ & OR (95\% CI) & P \\
\hline $3 / 3$ & 13 & 19 & $0.31(0.08-1.21)$ & 0.135 \\
\hline $2 / 3$ & 15 & 13 & $0.65(0.35-1.18)$ & 0.17 \\
\hline $2 / 2$ & 7 & 1 & $0.2(0.52-0.79)$ & $0.018^{*}$ \\
\hline
\end{tabular}

Our results showed that chronic hepatitis $C$ patients who had SLC11A1 2/2 genotype were significantly at decreased risk to develop fibrosis 0.2 times than those who had $3 / 3$ genotype. 
Table (7): Serum liver function tests in relation to SLC11A1 genotypes in chronic hepatitis C patients

\begin{tabular}{|l|c|c|c|c|}
\hline \multicolumn{1}{|c|}{ Parameters } & $\begin{array}{c}\mathbf{3 / 3} \\
\mathbf{N o =}(\mathbf{3 2})\end{array}$ & $\begin{array}{c}\mathbf{2 / 3} \\
\mathbf{N o =}(\mathbf{2 8})\end{array}$ & $\begin{array}{c}\mathbf{2 / 2} \\
\mathbf{N o =}(\mathbf{8})\end{array}$ & $\mathbf{P}$ \\
\hline ALT (IU/L) & $104 \pm 26.2$ & $92 \pm 15.7$ & $93 \pm 17.9$ & 0.211 \\
\hline AST (IU/L) & $85 \pm 20.1$ & $78 \pm 13.8$ & $82 \pm 12.4$ & 0.46 \\
\hline ALP (IU) & $170 \pm 40.3$ & $163 \pm 36.8$ & $161 \pm 33.4$ & 0.37 \\
\hline Albumin (gm/dl) & $3.7 \pm 0.43$ & $3.79 \pm 0.49$ & $3.8 \pm 0.52$ & 0.79 \\
\hline Total protein (gm/dl) & $8.1 \pm 2.2$ & $7.6 \pm 1.8$ & $8.2 \pm 1.5$ & 0.22 \\
\hline Total bilirubin (mg/dl) & $1.38 \pm 0.73$ & $1.42 \pm 0.81$ & $1.36 \pm 0.60$ & 0.5 \\
\hline Direct bilirubin $(\mathrm{mg} / \mathrm{dl})$ & $0.51 \pm 0.11$ & $0.49 \pm 0.13$ & $0.48 \pm 0.82$ & 0.13 \\
\hline
\end{tabular}

ALP: Alkaline phosphatase

\section{DISCUSSION}

Hepatitis $\mathrm{C}$ virus (HCV) is a leading cause of chronic liver disease, cirrhosis, and hepatocellular carcinoma, as well as the most common indication for liver transplantation in many countries [1].

Approximately $75 \%-85 \%$ of $\mathrm{HCV}$-infected persons will progress to chronic $\mathrm{HCV}$ infection. Progression to cirrhosis is usually clinically silent and a wide range of fibrosis rates occur [5].

The rate of progression to cirrhosis is highly variable, and is influenced by several factors, including the amount of alcohol consumption, age of initial HCV infection, HIV and HBV coinfection, and co-morbid conditions [1]. It is estimated that approximately 20 to $30 \%$ of those infected with HCV will develop cirrhosis during 20 to 30 year period after becoming chronically infected. This progression, however, is variable and it is impossible to predict the expected outcome for an individual early in the course of their disease [5]. Persons with cirrhosis are at increased risk of developing HCC [1].

Concerning the relation of SLC11A1 promoter gene polymorphism with the development of chronic hepatitis $\mathrm{C}$ and liver fibrosis, we determined the frequency of SLC11A1 genotypes in chronic hepatitis $\mathrm{C}$ patients without fibrosis, chronic hepatitis $\mathrm{C}$ patients with fibrosis, and control groups using subjects homozygous for common allele as a reference group.

No statistically significant difference of SLC11A1 genotype frequencies among chronic hepatitis $\mathrm{C}$ patients as compared to control group was observed in Egyptian population (P value 0.24).

These results are matched with Romero et al. [11] who investigated the possible role of the functional polymorphism located in the promoter region of SLC11A1 in the progression of fibrosis in chronic hepatitis $\mathrm{C}$ patients and reported an absence of the associations between SLC11A1 promoter gene polymorphism and the incidence of chronic hepatitis $\mathrm{C}$.

As regards, the association of SLC11A1 gene polymorphism with the progression of liver fibrosis, we found that the frequency of SLC11A1 $2 / 2$ genotype was significantly decreased in chronic hepatitis $\mathrm{C}$ group with fibrosis as compared to chronic hepatitis $\mathrm{C}$ group without fibrosis $(\mathrm{P}$ value $=0.01)$. Chronic hepatitis $\mathrm{C}$ patients who had SLC11A1 2/2 genotype were significantly at decreased risk to develop fibrosis 0.2 times than those who had $3 / 3$ genotype (OR:0.2, CI:[(0.52-0.79)] suggesting that the $2 / 2$ genotype is associated with an decreased susceptibility to develop fibrosis .

This finding is going in hand with Romero et al. [11] who observed that the association between SLC11A1 2/2 genotype and lack of fibrosis progression achieved statistical significance as the SLC11A1 homozygous 2/2 genotype was rarely detected among patients showing advanced fibrosis but was highly represented in those with fibrosis grade $(0,1)$ and added that patients carrying SLC11A1 allele 3 had high risk of advanced liver fibrosis, while those with SLC11A1 2/2 genotype had a protection against fibrosis progression.

Our results could be explained as SLC11A1 could regulate secretion of several cytokines such as tumor necrosis factor (TNF) and tumor growth factor (TGF-b21) which is involved in the activation of hepatic stellate cells and progression of fibrosis in chronic hepatitis C [12].

Romero et al. [11] reported that the SLC11A1 gene could modulate Kupffer cell activation with higher TNF production in individuals carrying SLC11A1allele 3. 
Fritsche et al. [13] found that SLC11A1 has been associated with increased nitric oxide production and enhanced inducible nitric oxide syntheses (iNOS) in hepatocytes and macrophages. Nitric oxide has been implicated in the pathogenesis of chronic hepatitis $\mathrm{C}$, mainly via peroxynitrite; a potential oxidant that is produced by the reduction of superoxide anion with nitric oxide [11].

This mechanism could explain the advanced fibrosis found in patients carrying SLC11A1 3/3 genotype.

Furthermore, IL-8 receptor gene is in an adjacent location to the SLC11A1 gene and this chemokine has been associated with viral persistence and resistance to interferon therapy [14].

As regards the relation of SLC11A1 gene polymorphism to the liver function tests. Our results were matched with Romero et al. [11], who found that that there was no statistically significant difference of liver function tests between SLC11A1 3/3 genotype carriers, SLC11A1 2/3 and2/2 genotype carriers.

In conclusion, the results of our study supported the suggestion that SLC11A1 gene promoter polymorphism could influence fibrosis progression in chronic hepatitis $\mathrm{C}$ in that the homozygous genotype $2 / 2$ exerts a protective effect against cirrhosis development.

Recommendation: This study draws attention to the importance of gene therapy in the prognosis of the HCV infection which needs further studies.

\section{Conflicts of interest: None \\ Funding:None. \\ Ethical approval:Approved.}

\section{REFERENCES}

1- Lee MH, Yang HI, Yuan Y, L'Italien G and Chen CJ . Epidemiology and natural history of hepatitis C virus infection. Hepatitis C virus 2014; 20 (28): 9270-9280.

2- Genovesi S, Prata Pizzala DM, Pozzi M, Ratti L, Milanese M, Vincenti A, et al. Baroreceptor sensitivity and baroreceptor effectiveness index in cirrhosis: the relevance of hepatic venous pressure gradient. Liver Int 2009; 3: 19-21.

3- Mohamoud YA, Mumtaz GR, Riome S Miller D and Abu-Raddad LJ. The epidemiology of hepatitis Cvirus in Egypt. BMC Infect Dis 2013; 13:288.
4- Kabiri M, Jazwinski AB, Roberts MS, Schaefer AJ and Chhatwal J. (2014). The Changing Burden of Hepatitis C Infection in the United States: Model-based Predictions. Ann. Intern. Med.2014; 161(3): 170-180.

5- Chen SL and Morgan TR .The Natural History of Hepatitis C Virus (HCV) Infection. International Journal of Medical Sciences 2006; 3(2):47-52.

6- Chang KM .Immunopathogenesis of hepatitis $\mathrm{C}$ virus infection. Clin. Liver Dis.2003; 7:89-105.

7- Sechi LA, Gazouli M, Sieswerda LE, Molicotti P, Ahmed N, Ikonomopoulos J, et al. Relationship between crohn's disease, infection with mycobacterium avium subspecies paratuberculosis and SLC11A1 gene polymorphisms in Sardinian patients. World J. Gastroenterol. 2006; 12 (44): 7161-7164.

8- Fitness J, Tosh K and Hill A .Genetics of susceptibility to leprosy. Genes and Immunity 2002; 3: 441-453.

9- Pugh RN, Murray-Lyon IM, Dawson JL, Pietroni MC and Williams R. Transection of the oesophagus for bleeding oesophageal varices. $\mathrm{Br}$ J Surg 1973 ; 60: 646-9.

10- Ouchi K, Suzuki Y, Shirakawa $T$ and Kishi F. Polymorphism of SLC11A1 (formerly NRAMP1) gene confers susceptibility to kawasaki disease.The jornal of infectious disease 2003; 187:326-329.

11- Romero-Gómez M, Montes-Cano MA, OteroFernández MA, Torres B, Sánchez-Muñoz D, Aguilar F, et al.SLC11A1 promoter gene polymorphisms and fibrosis progression in chronic hepatitis C. Gut 2004; 53:446-450.

12- Schuppan D, Krebs A, Bauer M and Hahn EG. Hepatitis C and liver fibrosis. Cell Death Differ 2003; 10 (1):S59-67.

13- Fritsche G, Nairz M, Libby SJ, Fang FC and Weiss G. Slc11a1 (Nramp1) impairs growth of Salmonella enterica serovar typhimurium in macrophages via stimulation of lipocalin-2 expression. J. Leukoc. Biol. 2012; 92(2):353-359.

14- Clément S, Pascarella S, Conzelmann S, GonelleGispert C, Guilloux K and Negro F. The hepatitis $\mathrm{C}$ virus core protein indirectly induces alphasmooth muscle actin expression in hepatic stellate cells via interleukin-8. J. Hepatology 2010; 52(5): 635-643.

Peer reviewer: Maged Bahgat, Professor of Tropical Medicine and Hepatogastroenterology, Faculty of Medicine, Zagazig University, Egypt. Editor: Tarik Zaher, Professor of Tropical Medicine and Hepatogastroenterology, Faculty of Medicine, Zagazig University, Egypt. 